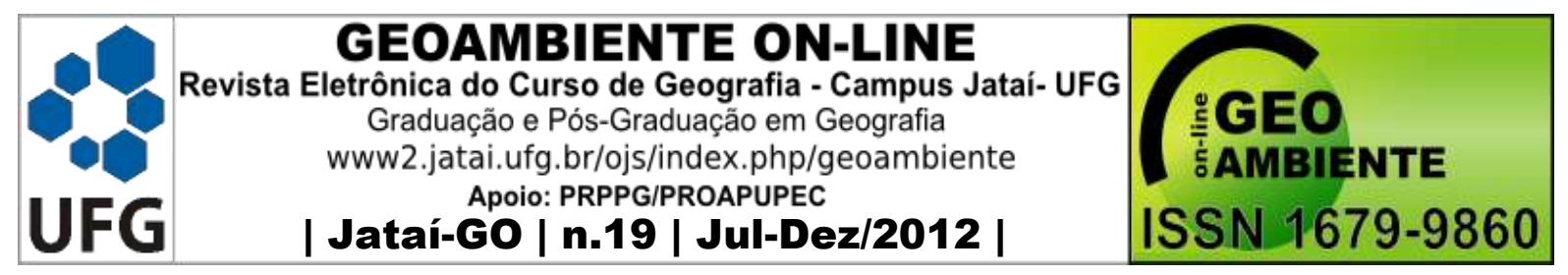

\title{
ÍNDICE DE ANOMALIA DE CHUVAS DO ESTADO DO TOCANTINS
}

Francisco F. N. Marcuzzo ${ }^{1}$ e Elvis R. P. Goularte ${ }^{2}$

(1 - Companhia de Pesquisa de Recursos Minerais / Serviço Geológico do Brasil CPRM/SGB - Eng', Doutor, Pesquisador em Geociências, Engenharia Hidrológica, Rua Banco da Província, $n^{\circ} 105$ - Santa Teresa - Porto Alegre/RS - CEP 90840-030, Tel.:(51) 3406-7300. francisco.marcuzzo@cprm.gov.br 2- Tecnólogo em Geoprocessamento, Mestrando em Geografia, Técnico em Reforma e Desenvolvimento Agrário - INCRA/SR-26, AANE 40 - QI. 08, lote 1/A - Alameda 01 CEP 77006-336 - Palmas/TO, Tel: (63) 32195217. geosigrichard@yahoo.com.br)

\section{Resumo}

A análise do comportamento das chuvas se torna importante uma vez que possibilita detectar tendências ou alterações no clima, em escalas locais, regionais, estaduais, nacionais e continentais. O presente trabalho teve como objetivo analisar a variação do Índice de Anomalia de Chuva (IAC) da precipitação pluvial no estado do Tocantins. Utilizaram-se dados de 43 estações pluviométricas distribuídas no estado, dados de 30 anos, 1977 a 2006, onde foram calculados os Índices de Anomalia de Chuva mensais para a classificação dos períodos secos e úmidos de acordo com a média local organizadas em médias temporais. Os resultados mostraram que a distribuição pluviométrica no estado do Tocantins apresenta uma grande variação nos índices interanuais precipitados em cada mês. No mês de janeiro, que é o mês mais úmido no estado do Tocantins, de 1977 a 2006, observou-se que o cálculo do IAC detectou 13 anos úmidos e 17 anos secos. Com a aplicação do IAC, para o período de estudo de 30 anos, pode-se concluir que houve um maior número de anos secos do que de anos úmidos, ou seja, houve uma tendência de diminuição das chuvas no estado do Tocantins para o período histórico estudado de 1977 a 2006.

Palavras-chave: Cerrado, climatologia, precipitação pluviométrica, pluviometria.

Artigo recebido para publicação em 19 de Agosto de 2012

Artigo aprovado para publicação em 18 de Novembro de 2012 


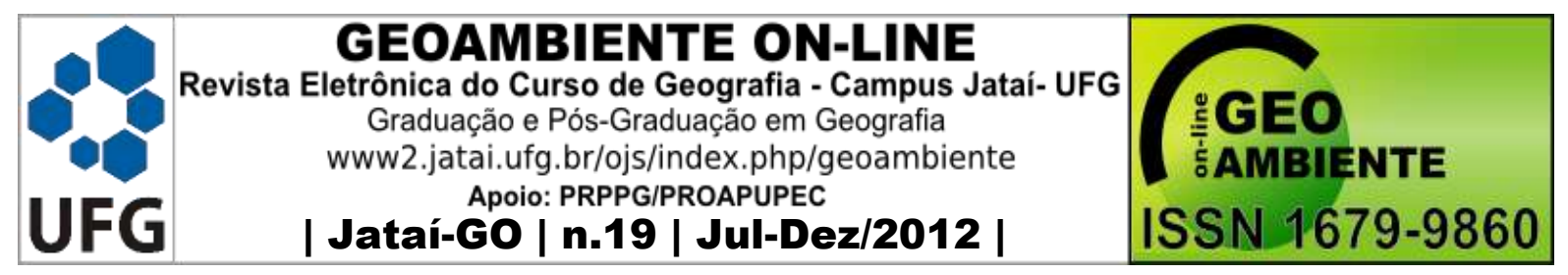

\section{Abstract}

\section{RAINFALL ANOMALY INDEX IN THE STATE OF TOCANTINS}

Analysis of the behavior of rainfall becomes important since it allows to detect trends or changes in climate on scales local, regional, state, national and continental. This study aimed to analyze the variation of the Rainfall Anomaly Index (RAI) of rainfall in the state of Tocantins. We used data from 43 rainfall stations distributed in the state, data from 30 years, from 1977 to 2006, where indices were calculated monthly rainfall anomaly for the classification of dry and wet periods in accordance with the local mean organized in temporal averages. The results showed that the rainfall distribution in the state of Tocantins has a large inter annual variation in precipitation rates in each month. In the month of January, which is the wettest month in the state of Tocantins, from 1977 to 2006, it was observed that the calculation of RAI detected 13 years wet and 17 dry years. With the application of RAI to the study period of 30 years, it can be concluded that there was a greater number of years that the dried wet years, so, there was a downward trend in Tocantins rain for the period history studied from 1977 to 2006.

Key words: Savannah, climatology, pluviometric precipitation, rainfall.

\section{Resumen}

\section{INDICE DE ANOMALÍA DE LA LLUVIA EN EL ESTADO DE TOCANTINS}

Análisis del comportamiento de las lluvias llega a ser importante ya que permite detectar tendencias o cambios en el clima a escala local, regional, estatal, nacional y continental. Este estudio tuvo como objetivo analizar la variación del índice de anomalía de lluvia (IAL) en el estado de Tocantins. Hemos utilizado los datos de 43 estaciones pluviométricas distribuidas en el estado, los datos de 30 años, de 1977 a 2006, donde los índices se calcularon anomalía de precipitación mensual para la clasificación de periodos secos y húmedos, de acuerdo con la media local organizada en promedios temporales. Los resultados mostraron que la distribución de las precipitaciones en el estado de Tocantins tiene una gran variación interanual en las tasas de precipitación en cada mes. En el mes de enero, que es el mes más lluvioso en el estado de Tocantins, de 1977 a 2006, se observó que el cálculo de la IAL 


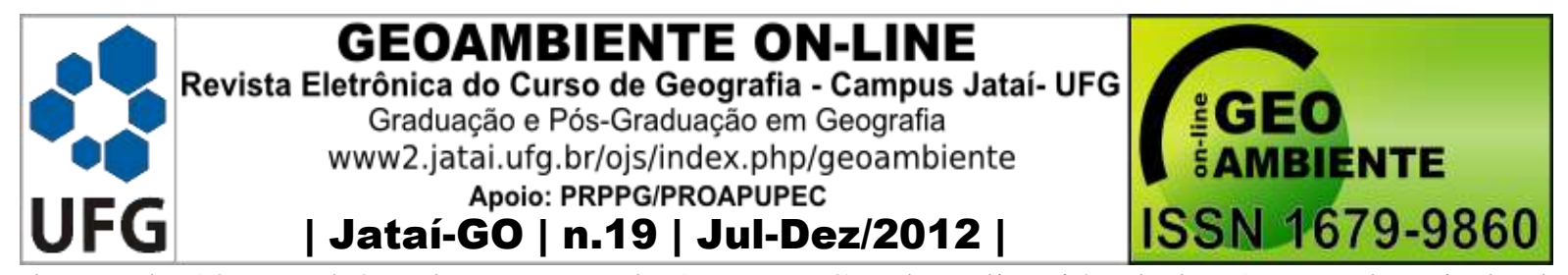

detectado 13 años húmedos y secos de 17 años. Con la aplicación de la IAL en el periodo de estudio de 30 años, se puede concluir que hubo un mayor número de años que los años húmedos secos, por lo que, hubo una tendencia a la baja en la lluvia Tocantins de la historia período estudiado 1977 a 2006 .

Palabras clave: Savannah, la climatología, precipitación pluviométrica, lluvia.

\section{1 - Introdução}

Um dos fenômenos físicos decorrentes da variabilidade climática são a variabilidade da precipitação pluvial, um importante fator no controle do ciclo hidrológico e uma das variáveis climáticas que maior influência exerce na transformação da paisagem e do meio ambiente.

As quantidades relativas de precipitação pluvial (volume), em seu regime sazonal ou diário (distribuição temporal) e as intensidades de chuvas individuais (volume/duração) são algumas das características que afetam direta ou indiretamente a população, a economia e o meio ambiente (BRITTO, BARLETA e MENDONÇA, 2006).

Marcuzzo et al. (2011), em estudo sobre mapeamento de chuvas no bioma Cerrado do estado de Tocantins, segundo a média histórica de 1977 a 2006, pode-se verificar que há uma maior percentagem de anos secos, 37,6\%, do que de anos úmidos, 62,4\%. Já em um estudo sobre a precipitação pluviométrica no bioma amazônico do estado do Tocantins, Marcuzzo, Goularte e Melo (2010) identificaram que o período chuvoso (nove meses) se estende de setembro a maio e o período seco (três meses) entre junho e agosto.

Morais et al. (2005) em um estudo sobre a climatologia das precipitações no estado do Pará com base em séries históricas de 23 anos (1976-1998) de dados diários de chuva, realizado em 31 localidades do estado, caracterizaram a variabilidade anual e sazonal com base no coeficiente de variação e no índice de variabilidade interanual relativo. A variação do coeficiente para a precipitação anual foi de foi de 15 a $30 \%$.

Robertson, Inês e Hansen (2007) utilizaram o modelo de Markov (NHMN) para fazer simulações estocásticas de março a agosto com precipitações diárias de dez estações no sudeste dos Estados Unidos, no período de 1923-1998. Este modelo foi aplicado para investigar a variação espacial e temporal das chuvas, em regiões de cultivo do milho. 


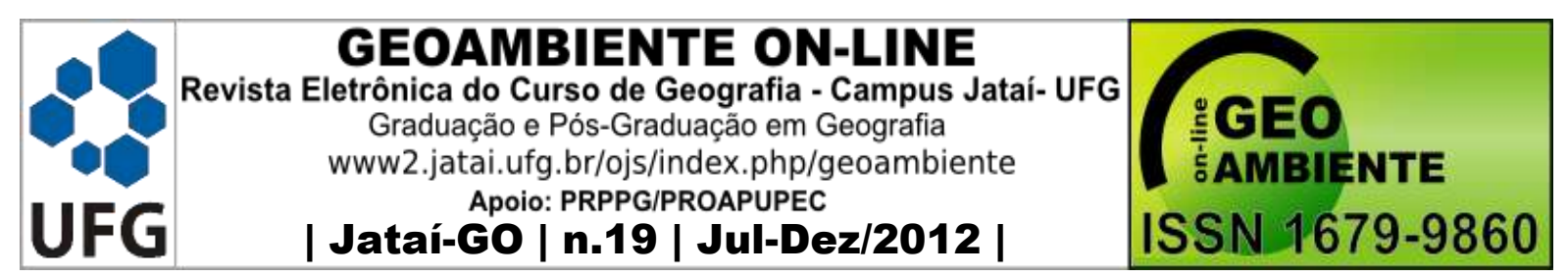

Segundo Da Silva (2009), com o emprego de índices climáticos, exemplo o IAC, pode-se desenvolver um sistema de acompanhamento das características dos períodos secos ou chuvosos, com informações anuais, sazonais ou mensais. Os índices climáticos facilitam conhecer profundamente a climatologia de uma região, e verificar os impactos que o clima global causa sobre a distribuição pluviométrica local, ou seja, a regionalização da precipitação para determinado local.

Um ponto crucial no emprego do IAC, bem como qualquer outro, reside na escolha do patamar a ser estabelecido para a definição de um período de seca. Esse patamar é, de modo geral, escolhido arbitrariamente. Já a escolha do patamar para a separação entre anos secos e úmidos não deve ser, portanto, arbitrária, mas deve ser escolhido com base no conhecimento climático da região, na análise das características dos períodos históricos de secas e das correspondentes consequências à população e ao meio ambiente atingido. Esses efeitos dependem, por sua vez, da infraestrutura hídrica existente, isto é, variam com o tempo (DA SILVA, 2009).

Da Silva et al. (2007), ao utilizarem o IAC para verificar a variabilidade das chuvas na bacia do rio Mundaú (AL e PE), encontraram uma modificação no padrão de distribuição de precipitação. Antes de 1974, nas sub-bacias do Médio Mundaú e Alto Mundaú, os anos foram mais secos e, após 1974, foram mais úmidos, ocorrendo o contrário no Baixo Mundaú.

Gonçalves et al. (2006) obtiveram o IAC para 15 estações situadas no Rio São Francisco, fato que mostrou que a incidência de anos secos é substancialmente maior na região estudada. Através da aplicação do índice em áreas situadas à jusante da hidrelétrica de Sobradinho, pode-se explicar a ocorrência de cheias e inundações ocorridas no sertão pernambucano.

Repelli et al. (1998) em um estudo sobre o IAC para o Estado do Ceará, concluíram que o índice proposto é apropriado para utilização em regiões semi-áridas e/ou tropicais, especialmente para a região Nordeste do Brasil. Observa-se a necessidade de mais estudos sobre precipitação pluviométrica utilizando o IAC nos demais Estados e regiões do país.

Estudos utilizando o IAC foram conduzidos por Freitas (2004 e 2005) para localidades do Estado do Ceará. Os autores observaram que com utilização do IAC é possível fazer uma 


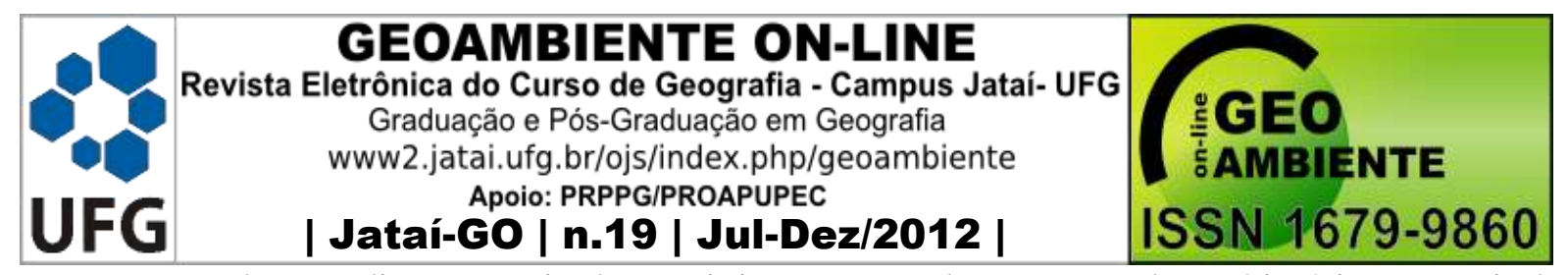

comparação das condições atuais de precipitação em relação aos valores históricos, servindo ainda para avaliar a distribuição espacial do evento, consoante com sua intensidade.

Park e Jung (2002) afirmaram que a modelagem de chuvas extremas é essencial, pois com a mesma pode-se minimizar custo em relação à agricultura e principalmente ter um bom entendimento em relação às modificações do clima e do tempo. A caracterização da variabilidade temporal de chuvas intensas é, ao longo de sua duração, imprescindível para quantificar adequadamente os efeitos ocasionados, de modo especial, ao controle do escoamento superficial em áreas urbanas e rurais (CRUCIANI, MACHADO e SENTELHAS, 2002; BEIJO et al., 2003).

Clarke e Silva (2004) sugeriram que as séries de dados têm que ser suficientemente longas e representativas do local de estudo, pois só assim pode-se observar a variabilidade do comportamento climático de uma região, principalmente em relação as chuvas intensas.

Ressalta-se que, no presente trabalho, não foi adotado um período-base de estudos para todas as estações, pois, ao analisar os dados disponíveis para as dez estações pluviográficas avaliadas, verificou-se que no caso de adotar um período comum de observações, ter-se-ia que descartar algumas estações da análise, visto que elas não tinham períodos coincidentes, em função do que se adotou como critério o uso de todo o período de dados disponível para cada estação, visando, desta forma, aumentar o período de obtenção das informações sobre chuvas intensas.

O objetivo deste trabalho é o de apresentar um estudo da variação temporal quantitativa da precipitação pluviométrica do estado do Tocantins num período de 30 anos, utilizando-se uma análise qualitativa do cálculo estatístico do Índice de Anomalia de Chuva.

\section{2 - Caracterização da vegetação e do clima do Estado do Tocantins}

O Estado do Tocantins (Figura 1) localizado na região norte do Brasil entre as longitudes $44^{\circ} \mathrm{W}$ e $52^{\circ} \mathrm{W}$ e latitudes $14^{\circ} \mathrm{S}$ e $4^{\circ} \mathrm{S}$, possui uma área de $277.620 \mathrm{~km}^{2}$ (ATLAS DO TOCANTINS, 2008) com 139 municípios (Figura 2). 


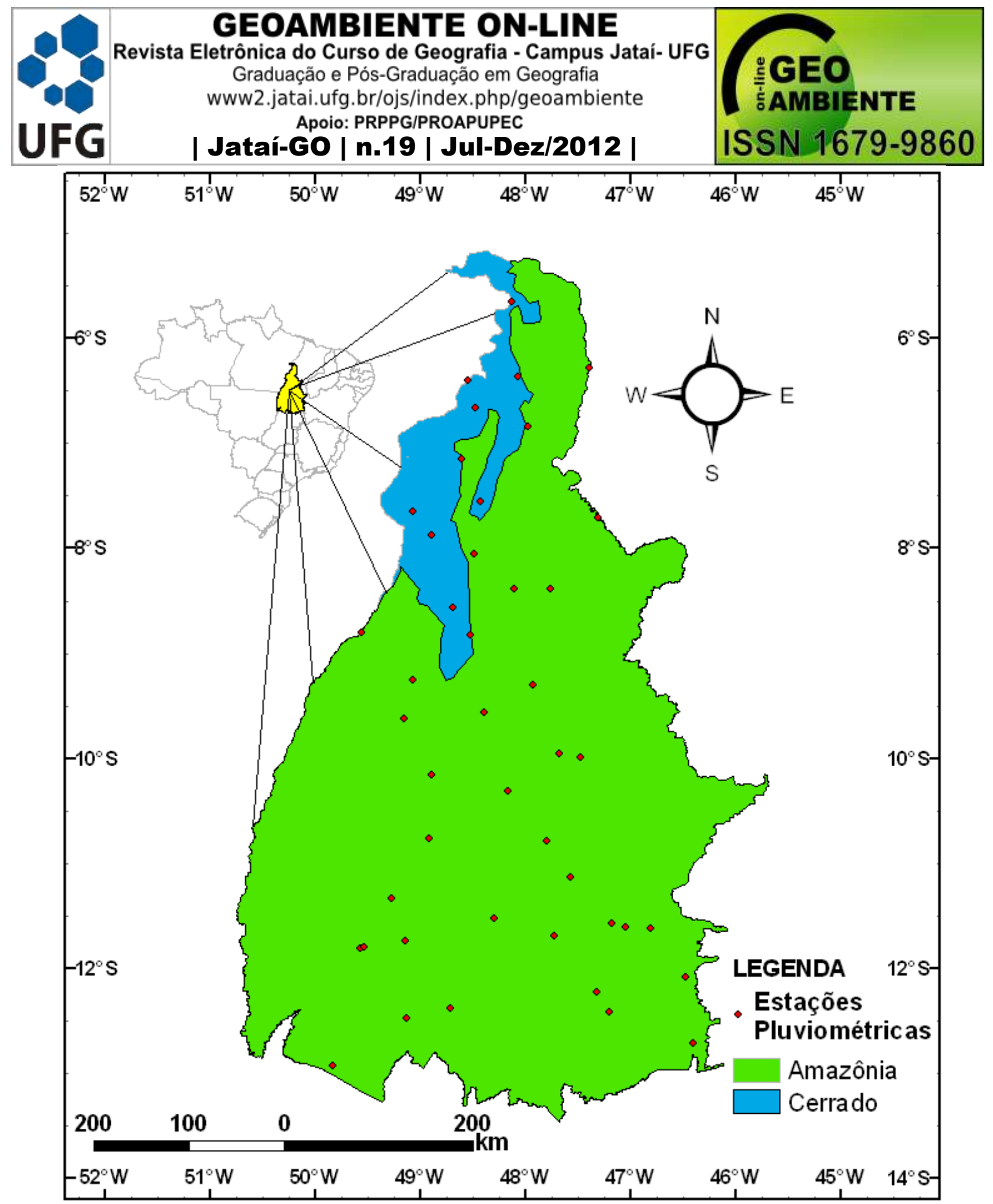

Figura 1 - Localização das estações pluviométricas utilizadas no estudo e os biomas (Cerrado e Amazônia) do estado do Tocantins.

Fonte: Elaborados pelos autores com dados de ANA (2010) e IBGE (2010). 


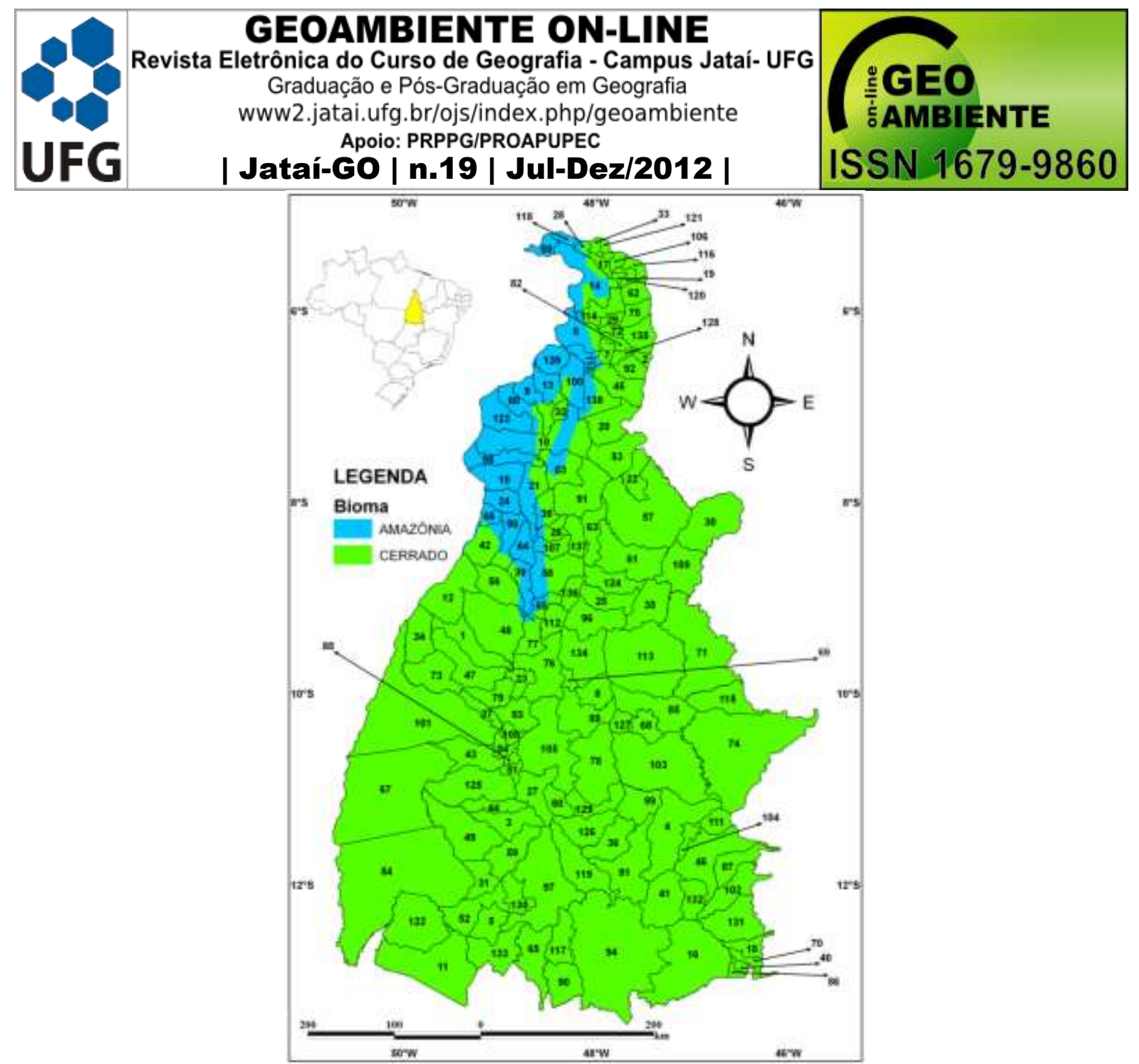

\begin{tabular}{|c|c|c|c|c|}
\hline \multicolumn{5}{|l|}{ Municípios } \\
\hline 1-Abreulândia & 29-Cachoeirinha & 57-Goiatins & 85-Novo Acordo & 113-Rio dos Bois \\
\hline 2-Aguiarnópolis & 30-Campos Lindos & 58-Guaraí & 86-Novo Alegre & 114-Sampaio \\
\hline 3-Aliança do Tocantins & 31-Cariri do Tocantins & 59-Gurupi & 87-Novo Jardim & 115-Sandolândia \\
\hline 4-Almas & 32-Carmolândia & 60-Ipueiras & 88-Oliveira de Fátima & 116-Santa Fé do Araguaia \\
\hline 5-Alvorada & 33-Carrasco Bonito & 61-Itacajá & 89-Palmas & 117-Santa Maria do Tocantins \\
\hline 6-Ananás & 34-Caseara & 62-Itaguatins & 90-Palmeirópolis & 118-Santa Rita do Tocantins \\
\hline 7-Angico & 35-Centenário & 63-Itapiratins & 91-Palmeirante & 119-Santa Rosa do Tocantins \\
\hline 8-Aparecida do Rio Negro & 36-Chapada da Natividade & 64-Itaporã do Tocantins & 92-Palmeiras do Tocantins & 120-Santa Tereza do Tocantins \\
\hline 9-Aragominas & 37-Chapada de Areia & 65-Jaú do Tocantins & 93-Paraíso do Tocantins & 121-Santa Terezinha do Tocantins \\
\hline 10-Araguaína & 38-Colinas do Tocantins & 66-Juarina & 94-Paranã & 122-Silvanópolis \\
\hline 11-Araguaçu & 39-Colméia & 67-Lagoa da Confusão & 95-Pau d'Arco & 123-São Bento do Tocantins \\
\hline 12-Araguacema & 40-Combinado & 68-Lagoa do Tocantins & 96-Pedro Afonso & 124-São Félix do Tocantins \\
\hline 13-Araguanã & 41-Conceição do Tocantins & 69-Lajeado & 97-Peixe & 125-São Miguel do Tocantins \\
\hline 14-Araguatins & 42-Couto de Magalhães & 70-Lavandeira & 98-Pequizeiro & 126-São Salvador do Tocantins \\
\hline 15-Arapoema & 43-Cristalândia & 71-Lizarda & 99-Pindorama do Tocantins & 127-São Sebastião do Tocantins \\
\hline 16-Arraias & 44-Crixás do Tocantins & 72-Luzinópolis & 100-Piraquê & 128-São Valério \\
\hline 17-Augustinópolis & 45-Darcinópolis & 73-Marianópolis do Tocantins & s 101-Pium & 129-Sítio Novo do Tocantins \\
\hline 18-Aurora do Tocantins & 46-Dianópolis & 74-Mateiros & 102-Ponte Alta do Bom Jesus & 130-Sucupira \\
\hline 19-Axixá do Tocantins & 47-Divinópolis do Tocantins & 75-Maurilândia do Tocantins & 103-Ponte Alta do Tocantins & 131-Taguatinga \\
\hline 20-Babaçulândia & 48-Dois Irmãos do Tocantins & is 76-Miracema do Tocantins & 104-Porto Alegre do Tocantins & 132-Taipas do Tocantins \\
\hline 21-Bandeirantes do Tocantins & s 49-Dueré & 77-Miranorte & 105-Porto Nacional & 133-Talismã \\
\hline 22-Barra do Ouro & 50-Esperantina & 78-Monte Santo do Tocantins & s 106-Praia Norte & 134-Tocantínia \\
\hline 23-Barrolândia & 51-Fátima & 79-Monte do Carmo & 107-Presidente Kennedy & 135-Tocantinópolis \\
\hline 24-Bernardo Sayão & 52-Figueirópolis & 80-Muricilândia & 108-Pugmil & 136-Tupirama \\
\hline 25-Bom Jesus do Tocantins & 53-Filadélfia & 81-Natividade & 109-Recursolândia & 137-Tupiratins \\
\hline 26-Brasilândia do Tocantins & 54-Formoso do Araguaia & 82-Nazaré & 110-Riachinho & 138-Wanderlândia \\
\hline 27-Brejinho de Nazaré & 55-Fortaleza do Tabocão & 83-Nova Olinda & 111-Rio Sono & 139-Xambioá \\
\hline 28-Buriti do Tocantins & 56-Goianorte & 84-Nova Rosalândia & 112-Rio da Conceição & \\
\hline
\end{tabular}

Figura 2 - Localização territorial dos municípios do Estado do Tocantins e os biomas.

Fonte: Elaborados pelos autores com dados de IBGE (2010). 


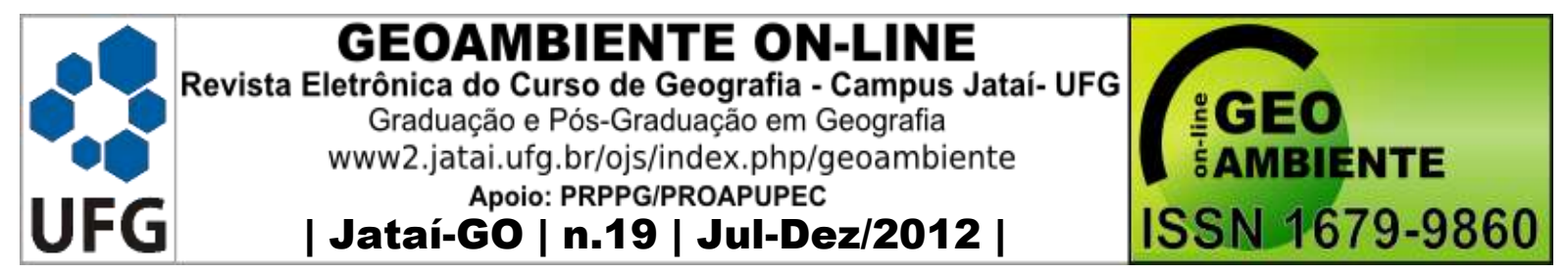

A parte inserida na Amazônia Legal equivale a cerca de 5,4\% do território do Estado do Tocantins (ATLAS DO TOCANTINS, 2008). Em termos de vegetação, o Tocantins é um dos nove estados que formam a região Amazônica. Sua vegetação de cerrado (87\% do território) divide espaço, sobretudo, com a floresta de transição amazônica (TOCANTINS, 2010). Os rios Tocantins, Araguaia, Paranã, Javaés, do Sono, Formoso, Santa Teresa, Manuel Alves Grande e do Côco são os mais importantes do estado (ATLAS DO TOCANTINS, 2008)

O clima da região é tropical semiúmido, controlado pelas massas de ar Equatorial Continental e Polar Atlântica. A massa equatorial, apesar de continental é uma massa úmida, em razão da presença de rios caudalosos e da intensa transpiração da massa vegetal da Amazônia, região que provoca chuvas abundantes e diárias, principalmente no verão e no outono (MONTEIRO, 1951). Os meses de outubro a abril são responsáveis por aproximadamente $90,16 \%$ de toda precipitação anual do estado. O período chuvoso da região coincide com a época em que a massa de ar equatorial continental atua. Sua atuação se dá especialmente durante a primavera-verão, quando temos sua atração para o interior do continente no sentido noroeste para sudeste, ou ainda para leste-sudeste, em decorrência dos recuos sofridos pela massa polar atlântica (MONTEIRO, 1951).

\section{3 - Índice de Anomalia de Chuva (IAC)}

Calcularam-se as médias temporais da precipitação para o período de estudo, necessárias para o cálculo do Índice de Anomalia de Chuva (IAC), o qual serve para classificar períodos secos ou úmidos de acordo com a média local (Quadro 1). Utilizou-se neste trabalho o IAC desenvolvido e testado por Rooy (1965), o qual é apresentado pelas seguintes equações:

$$
\begin{aligned}
& I A C=3\left[\frac{(N-\bar{N})}{(\bar{M}-\bar{N})}\right], \text { para anomalias positivas } \\
& I A C=-3\left[\frac{(N-\bar{N})}{(\bar{X}-\bar{N})}\right], \text { para anomalias negativas }
\end{aligned}
$$

em que, $N$ - precipitação mensal atual $\left(\mathrm{mm}^{\mathrm{m}} \mathrm{mes}^{-1}\right) ; \bar{N}$ - precipitação média mensal da série histórica (mm.mês $\left.{ }^{-1}\right) ; \bar{M}$ - média das dez maiores precipitações mensais da série histórica 


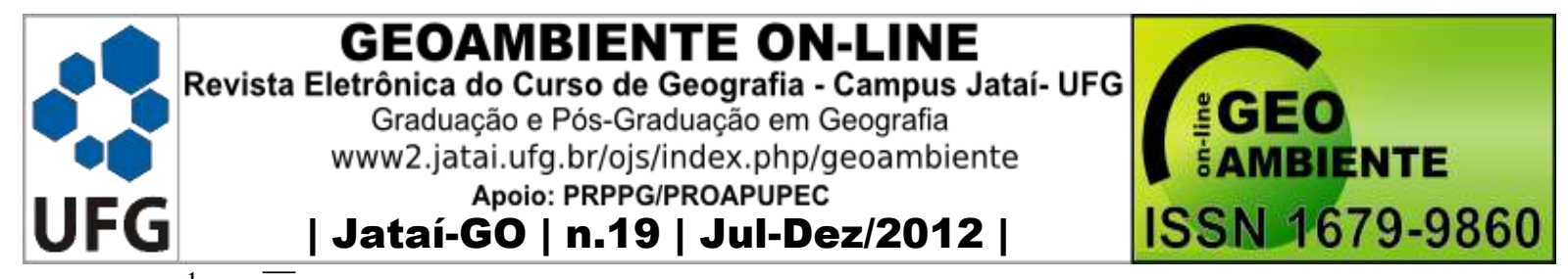

$\left(\mathrm{mm}_{\mathrm{mês}}{ }^{-1}\right)$ e $\bar{X}$ - média das dez menores precipitações mensais da série histórica (mm.mês $\left.{ }^{1}\right)$.

Quadro 1 - Classificação da pluviosidade segundo o Índice de Anomalia de Chuva.

\begin{tabular}{|c|l|}
\hline \hline Índice de Anomalia de Chuva (IAC) & \multicolumn{1}{|c|}{ Classificação da Pluviosidade } \\
\hline$\geq \mathrm{X}($ exemplo $\mathrm{X}=4)$ & Extremamente Chuvoso \\
\hline$\geq \mathrm{X}($ exemplo $\mathrm{X}=2) \mathrm{e}<\mathrm{X}($ exemplo $\mathrm{X}=4)$ & Muito Chuvoso \\
\hline$>0 \mathrm{e}<\mathrm{X}($ exemplo $\mathrm{X}=2)$ & Chuvoso \\
\hline 0 & Nem Chuvoso Nem Seco (Sem Anomalia) \\
\hline$<0 \mathrm{e}>\mathrm{X}($ exemplo $\mathrm{X}=-2)$ & Seco \\
\hline$\leq \mathrm{X}($ exemplo $\mathrm{X}=-2) \mathrm{e}>\mathrm{X}($ exemplo $\mathrm{X}=-4)$ & Muito Seco \\
\hline$\leq \mathrm{X}($ exemplo $\mathrm{X}=-4)$ & Extremamente Seco \\
\hline \hline
\end{tabular}

\section{4 - Dados utilizados no estudo do IAC}

Foram utilizados neste trabalho dados de precipitação mensal de 43 Estações Pluviométricas distribuídas no território Tocantinense (Figuras 1 e 2). Os dados foram obtidos diretamente do banco de dados físicos da CPRM/SGB (Companhia de Pesquisa de Recursos Minerais / Serviço Geológico do Brasil) e do sistema HidroWeb da ANA (2010) e o período de dados corresponde à série histórica de 1977 a 2006.

\section{5 - Análise dos resultados do Índice de Anomalia de Chuvas no Estado do Tocantins}

Conforme os resultados da Figura 3 verificou-se que o IAC do mês de janeiro, dos 30 anos, 13 anos foram úmidos e 17 anos foram secos. Para o mês de fevereiro foram 12 anos úmidos e 18 anos secos. No período úmido o maior ponto de inflexão, para o mês de janeiro, ocorreu no ano de 1985 e o menor foi em 1994, e, para o mês de fevereiro o maior ponto de inflexão foi no ano de 1980 e o menor ocorreu no ano de 2006. No período seco, para o mês de janeiro, o maior ponto de inflexão ocorreu no ano de 1993 e o menor no ano de 1977, enquanto que para o mês de fevereiro o maior ponto de inflexão foi no ano de 1981 e o menor no ano de 2005. 


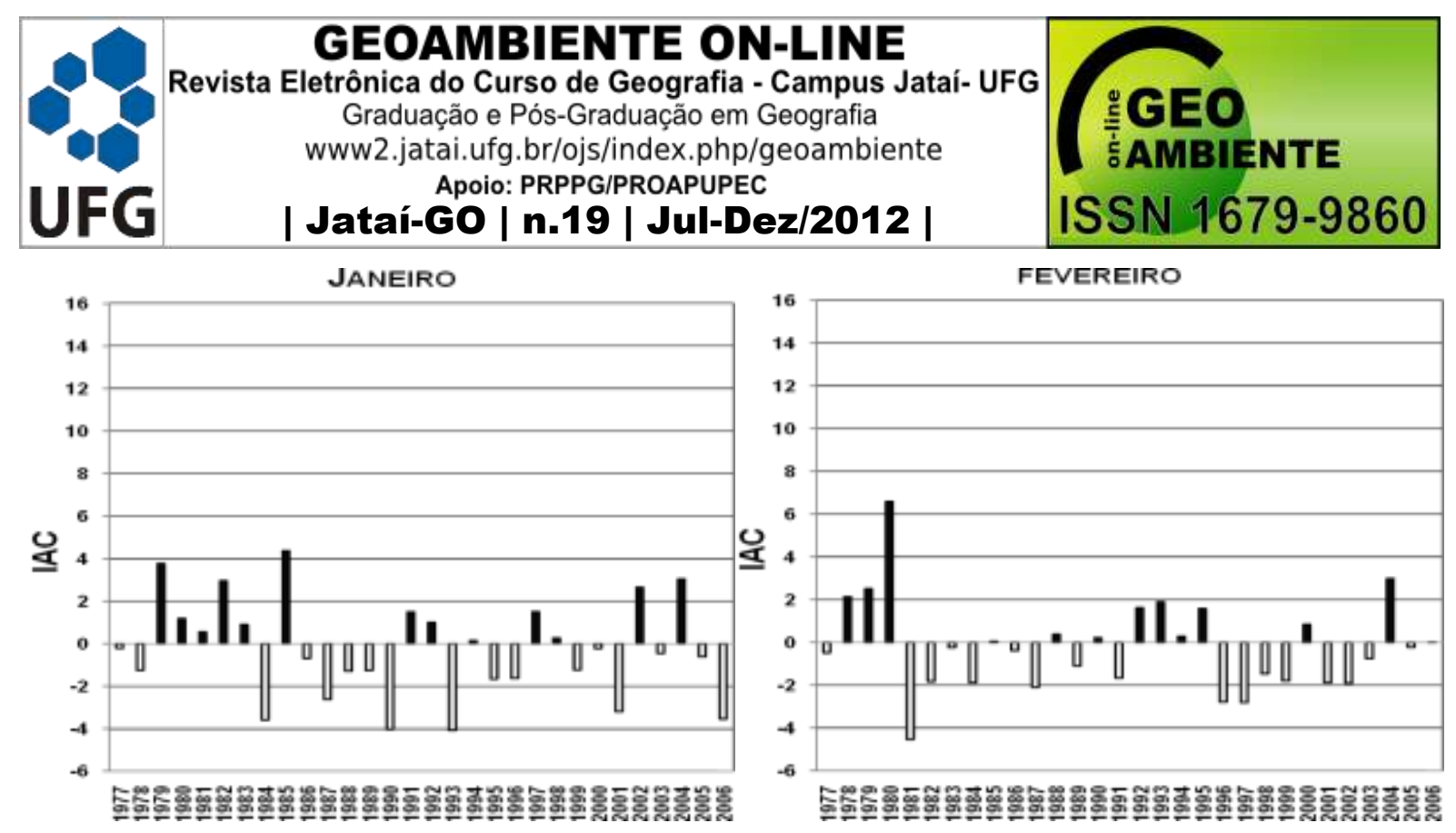

Figura 3 - IAC anual de 30 anos dos meses de janeiro e fevereiro do Tocantins.

Na Figura 4, o IAC do mês de março indicou que houve 14 anos úmidos contra os 16 anos secos. Para o mês de abril o IAC indicou 13 anos úmidos e 17 anos secos, diferença de um ano em relação ao mês anterior. Para o período úmido, do mês de março, o maior ponto de inflexão ocorreu no ano de 1997 e o menor no ano de 1986, e, para o mês de abril, o maior ponto de inflexão pertence ao ano de 2006 sendo o menor no ano de 1989. Já para o período seco, mês de março, o maior ponto de inflexão é no ano de 1980 e menor ponto no ano de 2004. Para mês de abril, o maior ponto ocorreu no ano de 1983 e o menor no ano de 1994 . Marcuzzo et al. (2012) observaram uma tendência de diminuição nos índices pluviométricos médios interanuais para a região Centro-Oeste e estado do Tocantins, na ordem de $-6,5 \%$. Os mesmos autores concluíram que apenas os meses de março e abril apresentaram crescimento da precipitação pluviométrica. 


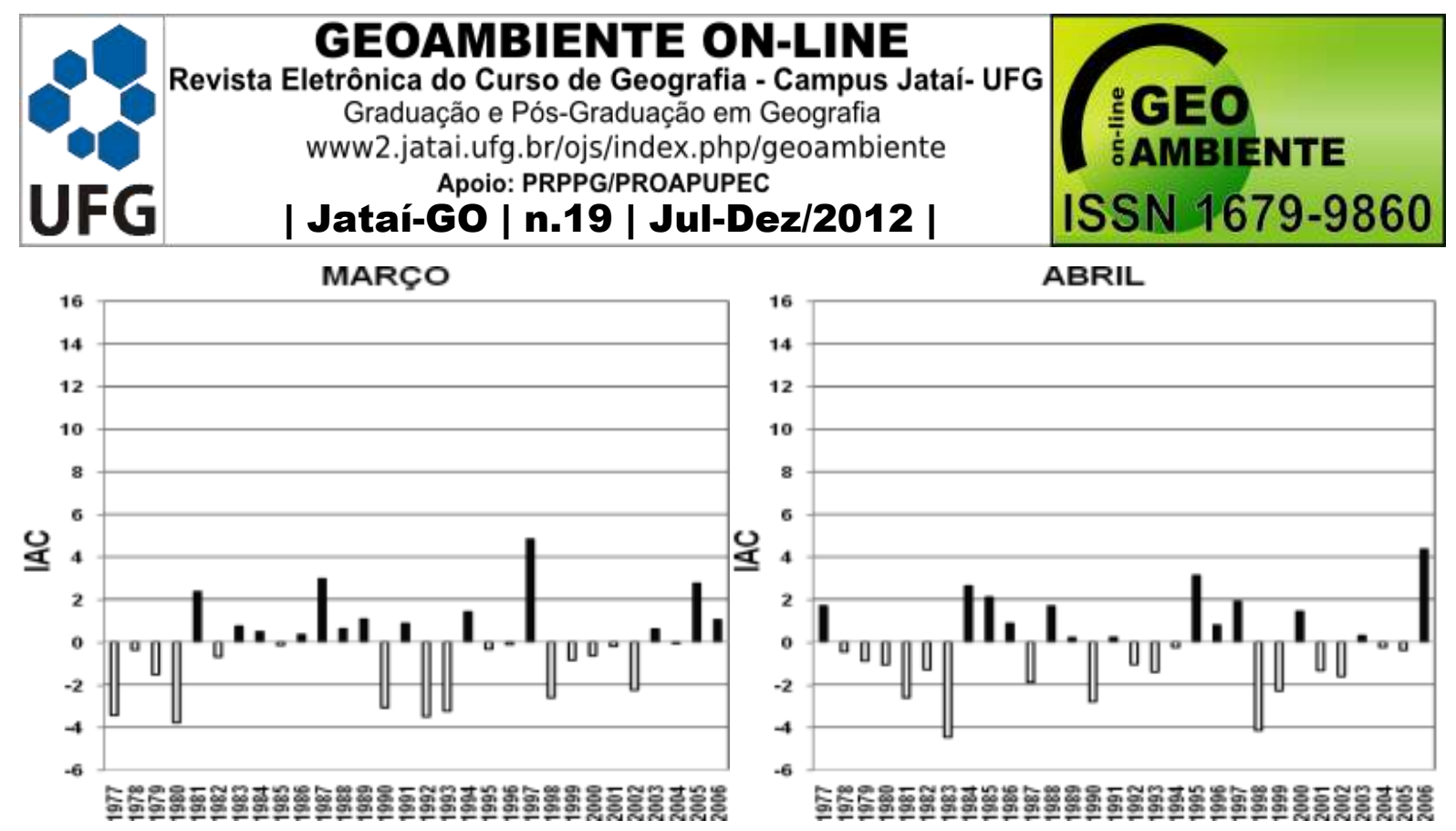

Figura 4 - IAC anual de 30 anos dos meses de março e abril do Tocantins.

Para o IAC da Figura 5, o mês de maio teve 12 anos úmidos contra 18 anos secos, e, seu maior ponto de inflexão, no período úmido, foi no ano de 1995 e o menor foi no ano de 2001. No período seco, o maior ponto de inflexão foi no ano de 1981 e o menor no ano de 1991. No mês de junho, o IAC, indicou que houve apenas 6 anos úmidos e 24 anos secos. Sendo que o maior ponto de inflexão para o período úmido, desse mês, foi no ano de 1978 e o menor foi no ano de1988. No período seco, o maior ponto de inflexão foi em 2006 e o menor foi em 2001.
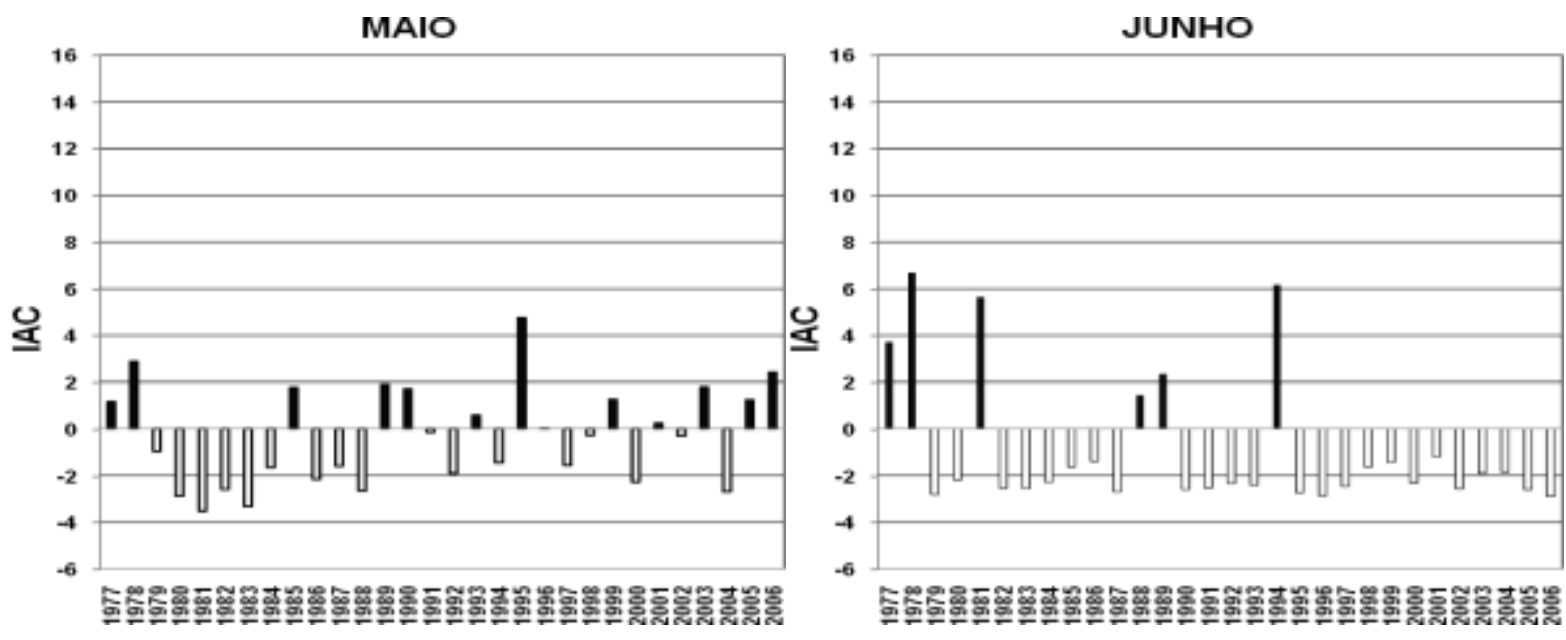

Figura 5 - IAC anual de 30 anos dos meses de maio e junho do Tocantins. 


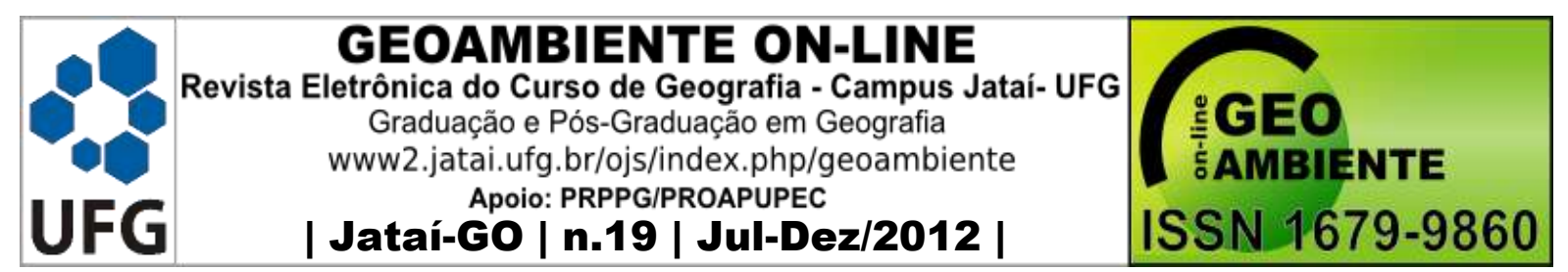

Infere-se na Figura 6 que o mês de julho teve a menor quantidade de anos úmidos, apenas cinco anos úmidos, e que o seu maior ponto de inflexão foi no ano de 1978 e o menor no ano de 2000. No período seco, para o mês de julho, houve 25 anos secos tendo o seu maior ponto de inflexão no ano de 2003 e o seu menor ponto foi no ano de 1986. Para o mês de agosto, observou-se que houve um aumento na quantidade dos anos úmidos, passando para 7 anos, e que seu maior ponto de inflexão foi no ano de 1979 e o menor no ano de 1989. Já para o período seco, do mês de agosto, o ano de maior ponto de inflexão foi no ano de 1995 e ficando com o menor ponto o ano de 2004.
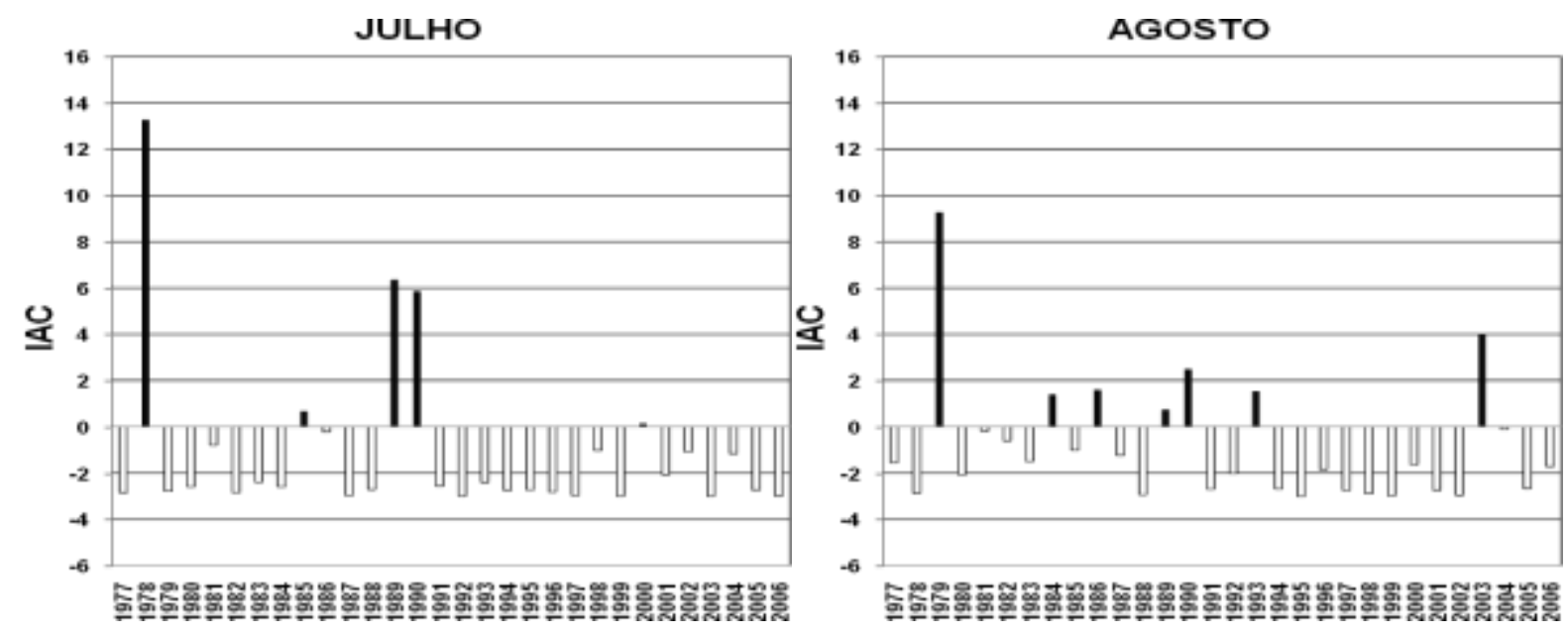

Figura 6 - IAC anual de 30 anos dos meses de julho e agosto do Tocantins.

De acordo com a Figura 7, no mês de setembro, pode-se observar que houve um acréscimo no total dos anos úmidos, 17 anos úmidos, e seu maior ponto de inflexão está no ano de 2000 e o menor está no ano de 1989. No mesmo mês, no período seco, o maior ponto de inflexão foi no ano de 1995 e o menor no ano de 2005. Para o mês de outubro houve um decréscimo no total do anos úmidos, passando para 15 anos, e seu maior ponto de inflexão foi no ano de 1985 e o seu menor foi no ano de 2004. Já para o período seco, o maior ponto de inflexão foi no ano de 2005 ficando o menor para o ano de 1990. 


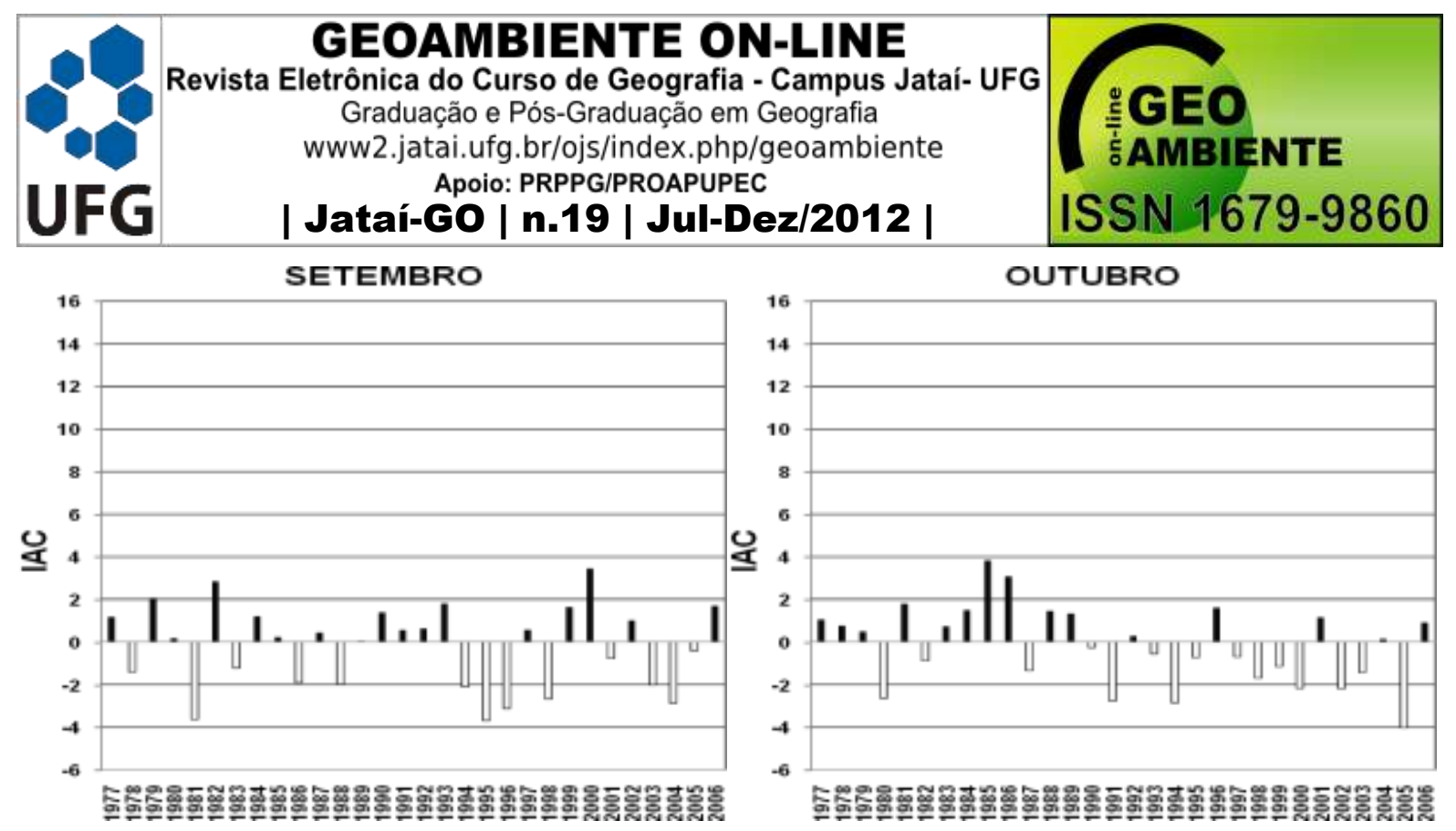

Figura 7 - IAC anual de 30 anos dos meses de setembro e outubro do Tocantins.

Os meses de novembro e dezembro, Figura 8 , mostra uma posição contrária ao que se imagina, pois, acha-se que por serem meses chuvosos apresentariam quantidades superiores aos demais meses no total de anos úmidos. Novembro teve 15 anos úmidos e seu maior ponto de inflexão foi no ano de 1980 e o menor no ano de 1991, e, dezembro teve 13 anos úmidos, com o maior ponto de inflexão no ano de 1989 e menor no ano de 1993. Para o período seco o mês de novembro teve seu maior ponto de inflexão no ano de 1984 e menor no ano de 1983, ficando o mês de dezembro com o maior ponto de inflexão, no período seco, no ano de 1981 e o menor no ano de 1995.
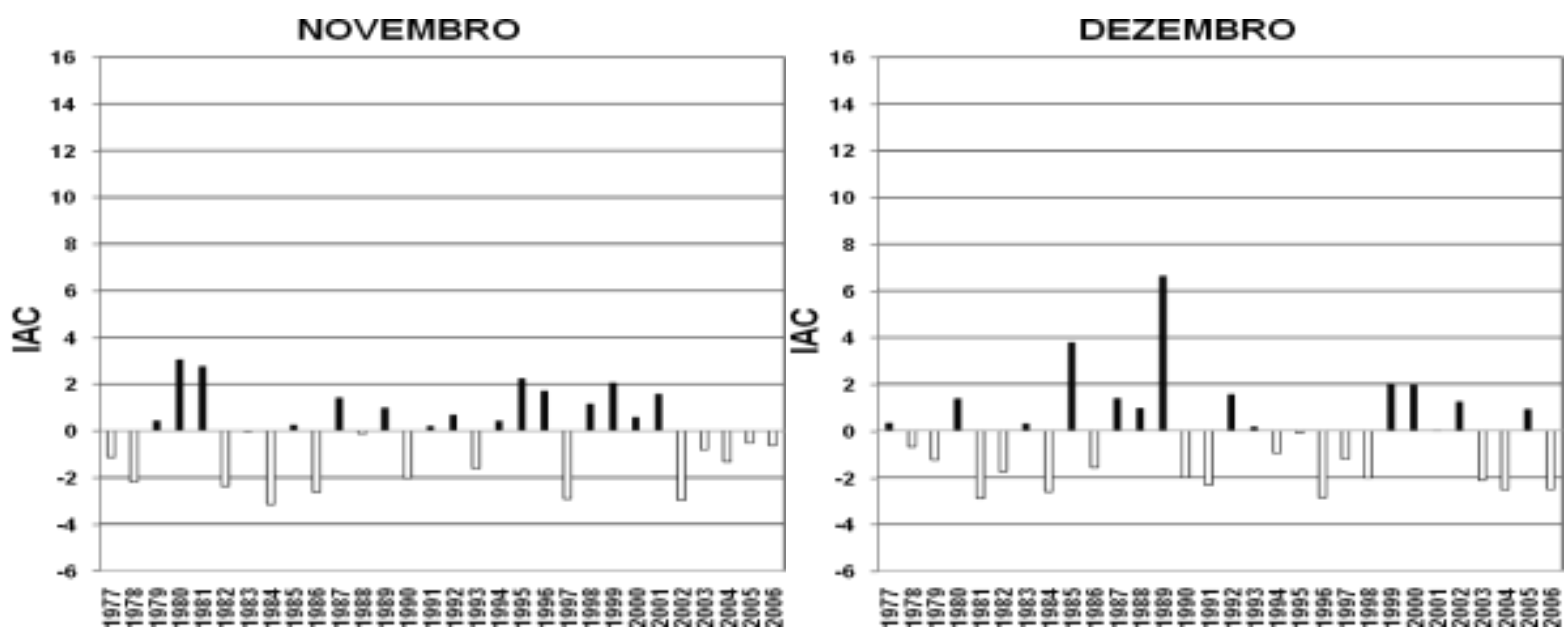

Figura 8 - IAC anual de 30 anos dos meses de novembro e dezembro do Tocantins. 


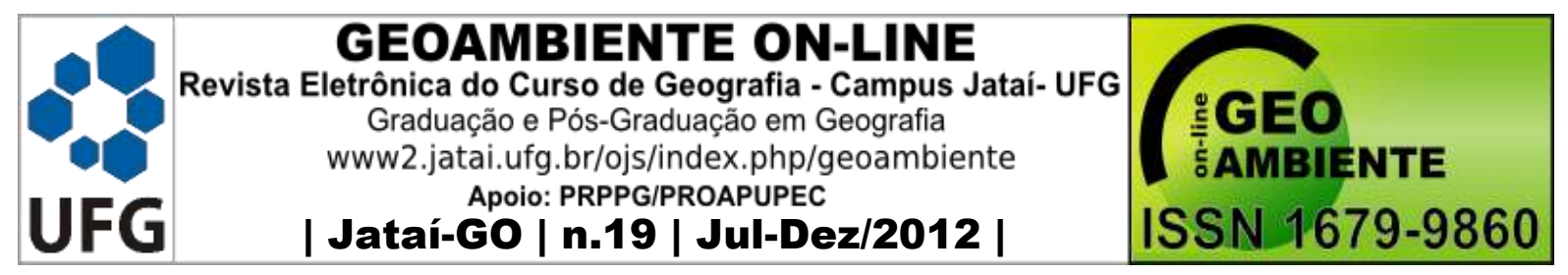

\section{6 - Conclusões}

Neste trabalho, analisou-se a distribuição dos índices pluviométricos do estado do Tocantins utilizando-se o cálculo do Índice de Anomalia de Chuva (IAC) para a verificação dos períodos secos e úmidos no estado do Tocantins segundo a média de 1977 a 2006.

Na média geral de 30 anos, de 1977 a 2006, observou-se, com a utilização do Índice de Anomalia de Chuvas, mais meses secos do que úmidos no estado do Tocantins. Os meses com menores volumes de precipitação pluviométrica no estado do Tocantins, de maio a setembro, foram os que apresentaram mais anomalias negativas em relação e média histórica.

Quanto à evolução temporal da precipitação anual, o período de 1990 a 2006 apresenta uma diminuição média da precipitação pluviométrica no estudo, e, ao utilizar o IAC, conclui que há uma mudança nos padrões de precipitação e que o "ponto de inflexão" médio, para o período úmido é no ano de 1989. Antes de 1989, para a média total anual, 9 anos são secos e 3 anos são úmidos, após o ano de 1989 são 17 anos secos.

Verifica-se neste estudo que o IAC pode ser utilizado como uma ferramenta para o acompanhamento interanual da precipitação pluviométrica do estado do Tocantins, visando determinar mudanças em seu regime de chuvas.

Em decorrência dos resultados deste trabalho, evidencia a necessidade de mais estudos relacionados ao comportamento climatológico, com ênfase a precipitação pluviométrica, para corroborar com o planejamento e zoneamento do estado do Tocantins e para melhorar o aproveitamento dos recursos naturais objetivando seu uso sustentável sem comprometer o regime pluviométrico do estado.

\section{7 - Agradecimentos}

Os autores agradecem à CPRM/SGB (Companhia de Pesquisa de Recursos Minerais / Serviço Geológico do Brasil) pelo fomento que viabilizou o desenvolvimento deste trabalho.

\section{8 - Referências Bibliográficas}




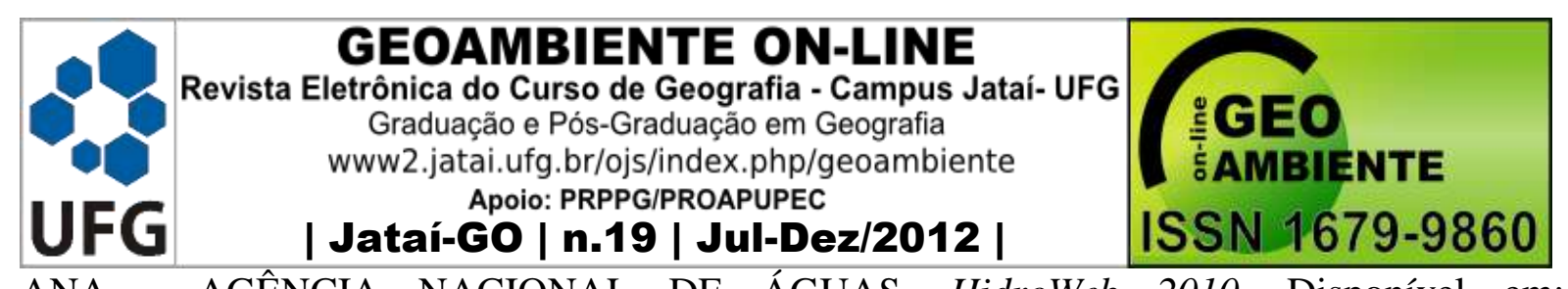

ANA - AGÊNCIA NACIONAL DE ÁGUAS. HidroWeb 2010. Disponível em:

<http://hidroweb.ana.gov.br/HidroWeb>. Acesso em 18 set. 2010.

ATLAS DO TOCANTINS: Subsídios ao Planejamento da Gestão Territorial. Secretaria do Planejamento - SEPLAN. Superintendência de Planejamento e Gestão Central de Políticas Públicas. Diretoria de Zoneamento Ecológico-Econômico - DZE. Organizado por Ricardo Ribeiro Dias, Eduardo Quirino Pereira e Lindomar Ferreira dos Santos. $5^{\mathrm{a}}$ ed. revista e atualizada. Palmas: SEPLAN, 2008.

BEIJO, L. A.; MUNIZ, J. A.; VOLPE, C. A.; PEREIRA, G. T. Estudo da precipitação máxima em Jaboticabal, SP, pela distribuição de Gumbel utilizando dois métodos de estimação dos parâmetros. Revista Brasileira de Agrometeorologia, v.11, n.1, p.141-147, 2003.

BRITTO, F.; BARLETTA, R.; MENDONÇA, M. Regionalização Sazonal e Mensal da Precipitação Pluvial Máxima no Estado do Rio Grande do Sul. Revista Brasileira de Climatologia, ISSN 1980-055X, Associação Brasileira de Climatologia, Presidente Prudente, SP. v. $02, \quad \mathrm{n}^{\circ}$ 02, 2006. p. 35 - 51. Disponível em: <http://ojs.c3sl.ufpr.br/ojs2/index.php/revistaabclima/article/viewFile/25385/17011>. Acesso em 18 ago. 2012.

CLARKE, R. T.; SILVA, B. C. Análise estatística de chuvas intensas na bacia do rio São Francisco. Revista Brasileira de Meteorologia, v.19, n.3, p. 265-272, 2004.

CRUCIANI, D. E.; MACHADO, R. E.; SENTELHAS, P. C. Modelos da distribuição temporal de chuvas intensas em Piracicaba, SP. Revista Brasileira de Engenharia Agrícola e Ambiental, v. 6, n. 1, p. 76-82, 2002. Disponível em: <http://www.scielo.br/scielo.php?pid=S1415-43662002000100014\&script=sci_arttext $>$.

Acesso em 19 ago. 2012.

DA SILVA, D. F. Análise de aspectos climatológicos, agroeconômicos, ambientais e de seus efeitos sobre a bacia hidrográfica do rio Mundaú (AL e PE). Tese (Doutorado em Recursos Naturais) - Universidade Federal de Campina Grande, Campina Grande, 2009. Disponível em:

<http://www.dominiopublico.gov.br/pesquisa/DetalheObraForm.do?select_action=\&co_obra $=153508>$. Acesso em 19 ago. 2012. 


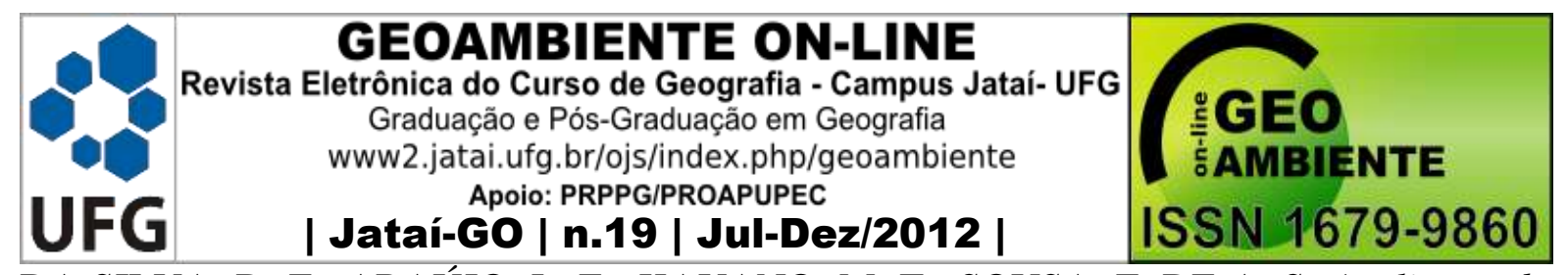

DA SILVA, D. F.; ARAÚJO, L. E.; KAYANO, M. T.; SOUSA, F. DE A. S. Avaliação dos impactos da variabilidade climática na distribuição pluviométrica da Bacia do Rio Mundaú através do IAC. In: Simpósio Brasileiro de Desastres Naturais e Tecnológicos, 2, 2007, Santos: [S.n.], 2007. v. 72.

FREITAS, M. A. S. A. Previsão de Secas e a Gestão Hidroenergética: O Caso da Bacia do Rio Parnaíba no Nordeste do Brasil. In: Seminário Internacional sobre Represas y Operación de Embalses, 2004, Puerto Iguazú. Anais... Puerto Iguazú : CACIER, 2004. v. 1. p. 1.

FREITAS, M. A. S. Um Sistema de Suporte à Decisão para o Monitoramento de Secas Meteorológicas em Regiões Semi-Áridas. Revista Tecnologia, Fortaleza, v. Suplem, p. 84-95, 2005. Disponível em: <http://pt.scribd.com/doc/17656360/Um-Sistema-de-Suporte-aDecisao-para-o-Monitoramento-de-Secas-Meteorologicas-em-Regioes-Semiaridas>. Acesso em 18 ago. 2012.

GONÇALVES, W.A.; CORREIA, M.F.; ARAÚJO, L.E.; DA SILVA, D.F.; ARAÚJO, H.A. Vulnerabilidade Climática do Nordeste Brasileiro: Uma análise de eventos extremos na Zona Semi-árida da bacia hidrográfica do São Francisco, XIV Congresso Brasileiro de Meteorologia, Anais... Florianópolis, 2006.

IBGE - INSTITUTO BRASILEIRO DE GEOGRAFIA E ESTATÍSTICA. Censo e Mapas 2010. Disponível em: 〈http://www.ibge.gov.br/cidadesat/link.php?uf=to >. Acesso em: 06/2012.

MARCUZZO, F. F. N.; GOULARTE, E. R. P.; MELO, D. C. R. Mapeamento Espacial, Temporal e Sazonal das Chuvas no Bioma Amazônico do Estado do Tocantins. In: X Simpósio de Recursos Hídricos do Nordeste, 10, 2010. Anais. Disponível em: $<$ http://www.cprm.gov.br/publique/media/Evento_biomaamazonico_Marcuzzo.pdf $>$. Acesso em 18 ago. 2012.

MARCUZZO, F. F. N.; GOULARTE, E. R. P.; MELO, D. C. R.; PINTO FILHO, R. F.; CARDOSO, M. R. D. Mapeamento espacial, temporal e sazonal das chuvas no bioma Cerrado do estado do Tocantins. In: Simpósio Brasileiro de Sensoriamento Remoto, 15, 2011, Curitiba-PR. Anais eletrônicos. Curitiba: SBSR, p. 4594-4601. Disponível em: <http://www.dsr.inpe.br/sbsr2011/files/p1700.pdf >. Acesso em: 28 dez. 2011. 


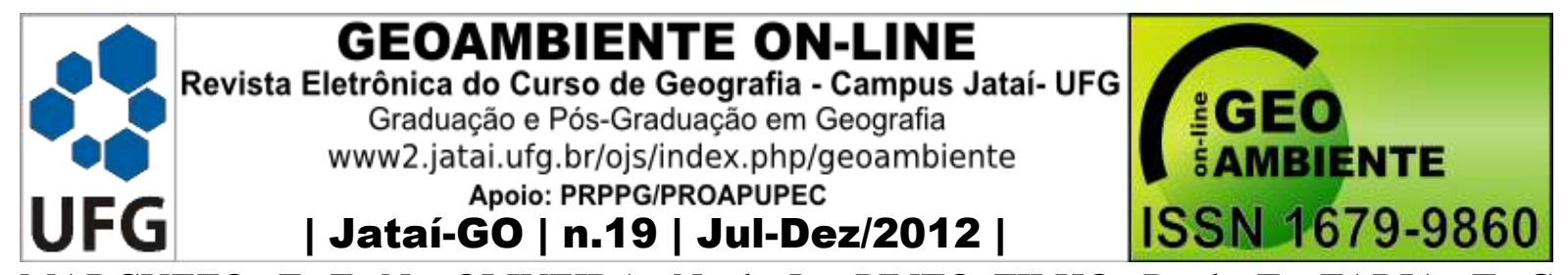

MARCUZZO, F. F. N.; OLIVEIRA, N. de L.; PINTO FILHO, R. de F.; FARIA, T. G.

Chuvas na região Centro-Oeste e no Estado do Tocantins: análise histórica e tendência futura. Boletim de Geografia, v. 30, p. 19-30, 2012. Disponível em: 〈http://periodicos.uem.br/ojs/index.php/BolGeogr/article/view/13418/9371>. Acessado em 6 de agosto de 2012. (http://dx.doi.org/10.4025/bolgeogr.v30i1.13418).

MONTEIRO, C. A. F. Notas para o estudo do clima do Centro-Oeste brasileiro. Rio de Janeiro, Revista Brasileira de Geografia, v. 13, n. 1, p.3-46, 1951.

MORAIS, B. C. de; COSTA, J. M. N. da; COSTA, A. C. L. da; e COSTA, M. H. Variação espacial e temporal da precipitação no Estado do Pará. Acta Amazonica. 2005, vol. 35, n. 2, pp. 207-214. Disponível em: <http://www.scielo.br/scielo.php?script=sci_arttext\&pid=S004459672005000200010\&lng=en\&nrm=iso>. ISSN 0044-5967. Doi: 10.1590/S004459672005000200010. Acesso em 10 ago. 2012.

PARK, J. S.; JUNG, H. S. Modeling Korean extreme rainfall using a Kappa distribution and maximum likelihood estimate. Theoretical and Applied Climatology. v.72, p. 55-64. 2002. Disponível em: <http://www.springerlink.com/content/wuenr8780cwdr1v4/>. Acesso em 18 ago. 2012.

REPELLI, C. A.; FERREIRA, N. S.; ALVES, J. M. B.; NOBRE, C. A. Índice de anomalia de precipitação para o Estado do Ceará. In: X Congresso Brasileiro de Meteorologia e VIII Congresso da Fllsmet, 1998, Brasília DF. Anais do X Congresso Brasileiro de Meteorologia e Viii Congresso da Fllsmet, 1998.

ROBERTSON, A. W.; INÊS, A. V. M.; HANSEN, J. W. Downscaling of Seasonal Precipitation for Crop Simulation. Journal of Applied Meteoroloy and Climatology, New York, June, 2007. Disponível em: 〈http://journals.ametsoc.org/doi/pdf/10.1175/JAM2495.1>. Acesso em 18 ago. 2012.

ROOY, M.P. van, A rainfall anomaly index independent of time and space. Notos,v. 14, 1965. 43 p.

TOCANTINS. Portal de Informações e Serviços do Estado do Tocantins. Características do Tocantins. 2010. Disponível em: <http://to.gov.br/tocantins/2>. Acesso em 18 ago. 2012. 